\begin{tabular}{|c|l|}
\hline Title & Prospective Risk of Intrauterine Fetal Death in Monoamniotic Twin Pregnancies \\
\hline Author(s) & Morikawa, Mamoru; Y amada, Takashi; Y amada, Takahiro; Sato, Shoji; Minakami, Hisanori \\
\hline Citation & $\begin{array}{l}\text { Twin Research and Human Genetics, 15(4), 522-526 } \\
\text { https://doi.org/10.1017/thg.2012.30 }\end{array}$ \\
\hline Issue Date & 2012-08 \\
\hline Doc URL & http://hdl.handle.net/2115/49741 \\
\hline Type & article \\
\hline File Information & S1832427412000308a.pdf \\
\hline
\end{tabular}

Instructions for use 


\title{
Prospective Risk of Intrauterine Fetal Death in Monoamniotic Twin Pregnancies
}

\author{
Mamoru Morikawa, ${ }^{1}$ Takashi Yamada, ${ }^{1}$ Takahiro Yamada, ${ }^{1}$ Shoji Sato, ${ }^{2}$ and Hisanori Minakami ${ }^{1}$ \\ ${ }^{1}$ Department of Obstetrics and Gynecology, Hokkaido University Graduate School of Medicine, Sapporo, Japan \\ ${ }^{2}$ Maternal and Perinatal Care Center, Oita Prefectural Hospital, Oita, Japan
}

\begin{abstract}
This study was conducted to review the overall short-term outcome of monoamniotic twins in Japan and to determine the prospective risk of fetal death so as to adequately counsel parents with monoamniotic twins. Study subjects were 101 women with monoamniotic twins who were registered with the Japan Society of Obstetrics and Gynecology Successive Pregnancy Birth Registry System and who had given birth at $\geq 22$ weeks of gestation during 2002-2009. The gestational week at delivery (mean $\pm S D$ ) was $31.8 \pm 3.7$. Fourteen women experienced intrauterine fetal death (IUFD). Short-term outcomes of co-twins born to the 14 women included 8 IUFDs, one early neonatal death within 7 days of life (END), and 5 survivors. Four other women experienced 5 ENDs. Thus, $13.9 \%$ (28/202) of infants died perinatally (22 IUFDs and 6 ENDs), $13.9 \%(14 / 101)$ of women experienced IUFD, and $82.2 \%$ (83/101) of women experienced neither IUFD nor END. Structural anomalies and twin-to-twin transfusion syndrome explained $17.9 \%$ (five infants) and $10.7 \%$ (three infants) of the 28 perinatal deaths, respectively. The prospective risk of IUFD was $13.9 \%$ (14/101) for women who reached gestational week $22^{-0 / 7}$, gradually decreasing thereafter but remaining at between $4.5 \%$ and $8.0 \%$ between gestational week $30^{-0 / 7}$ and $36^{-0 / 7}$.
\end{abstract}

- Keywords: monoamnionicity, preterm birth, prospective risk, twin

Monoamniotic twins occur in approximately $1 \%$ of monozygotic twin pregnancies. Monoamniotic twins are at increased risk of preterm delivery and fetal/neonatal death. The causes of these deaths include cord accidents, cord entanglement, and structural anomalies of the infants (Lewi, 2010). A perinatal mortality of $30-70 \%$ has been reported (Beasley et al., 1999). However, improvement of ultrasonographic resolution has enabled the detection of monoamniotic twinning during an early stage of pregnancy, and intensified monitoring of such twins may have reduced the overall perinatal mortality (Hack et al., 2009; Heyborne et al., 2005). However, the prospective risk of intrauterine fetal death (IUFD) according to gestational week has not been extensively studied.

This retrospective study was conducted to review the overall short-term outcome of monoamniotic twins in Japan and to determine the prospective risk of IUFD so as to adequately counsel parents with monoamniotic twins.

\section{Materials and Methods}

This study was approved by the Ethics Committee of Hokkaido University Hospital. A total of 101 women with monoamniotic twin pregnancies were studied. Data on these 101 women were abstracted from the Japan Society of Obstetrics and Gynecology Successive Pregnancy Birth Registry System (JSOG-SPBRS), in which approximately 120 secondary and tertiary hospitals participated and provided information on successive deliveries that occurred at $\geq 22$ weeks of gestation in these hospitals. Approximately 60,000 women were registered annually. The available information from this system included maternal age, parity, gestational week at delivery, chorionicity of the placenta, sex of the infants, birthweight, live-born/stillborn, early neonatal death within 7 days after birth, delivery mode, use of assisted reproductive techniques, maternal complications such as preterm premature rupture of membranes (PPROM), pregnancy-induced hypertension (PIH) including gestational hypertension and pre-eclampsia, placental abruption, placenta previa, twin-to-twin transfusion

RECEIVED 2 June 2011; ACCEPTED 7 October 2011.

ADDRESS FOR CORRESPONDENCE: Mamoru Morikawa, Department of Obstetrics and Gynecology, Hokkaido University School of Medicine, Kita-ku N15 W7, Sapporo 060-8638, Japan. E-mail:mmamoru@med.hokudai.ac.jp 
syndrome (TTTS), hyperglycemia, and structural abnormalities of the infants. A possible cause of death was sometimes described as a special reference for infants with perinatal mortality. These 101 women all had monoamniotic twin pregnancies (maternities) that were registered in this system during an 8-year period between January 2002 and December 2009, corresponding to approximately $0.5 \%$ of approximately 20,000 twin pregnancies that were registered during the study period.

Confirmation and/or diagnoses of various conditions such as placental amnionicity and TTTS depended on the institutions that participated in this registry system. However, we have guidelines for the management of twin pregnancies in Japan (JSOG and JAOG, 2011). According to the guidelines, it is recommended not to determine chorionicity until the end of 10 weeks of gestation, to count the numbers of chorions and amnions using ultrasonography, to diagnose as diamniotic in cases of monochorionic twins with a thin dividing membrane, to presume monoamniotic twins and repeat the ultrasonography examination in cases with an unrecognizable dividing membrane, to determine amnionicity (mono- or di-) before 14 weeks of gestation, to examine using ultrasonography at least once every 2 weeks in cases with monochorionic diamniotic twin pregnancy, paying attention to discordances in volumes of the amniotic fluid and/or fetal development, to presume TTTS and examine extensively in a case with a tendency toward polyhydramnios in one twin and oligohydramnios in the co-twin, and to diagnose as TTTS when one twin exhibited polyuric polyhydramnios, with the deepest vertical pool measuring at least $8 \mathrm{~cm}$, and the co-twin exhibited oliguric oligohydramnios, with the deepest vertical pool measuring at most $2 \mathrm{~cm}$.

We focused on the short-term outcomes of twins, including IUFD, early neonatal death within 7 days of life (END), and survivors until 7 days after birth (Alive). The prospective risk of at least a single IUFD at gestational week $N$ can be obtained using the following equation: number of all women who experience a single IUFD and a double IUFD at $\geq$ gestational week $N /$ number of all women who give birth at $\geq$ gestational week $N$ (Minakami et al., 1993).

Statistical analyses were performed using the statistical software package StatView 5.0 for Macintosh (SAS Institute Inc. Cary, NC, USA). All the data were presented as the mean $\pm S D$.

\section{Results}

The mean gestational week at delivery was $31.8 \pm 3.7$ (Table 1). Ninety $(89.2 \%)$ women underwent a cesarean delivery. Sixty-four $(63.4 \%)$ and 32 (31.7\%) women gave birth to twins at $<34$ and $<30$ weeks of gestation, respectively. Female-female pairs accounted for 55.4\% (56/101). Double IUFD and double END occurred in eight and one women, respectively. A total of 28 perinatal deaths (22 IUFDs and
TABLE 1

Demographic Characteristics of 101 Women

\begin{tabular}{ll}
\hline Age (years) & $29.6 \pm 4.8$ \\
$\geq 35$ years old & $11(10.9 \%)$ \\
Nullipara & $66(65.3 \%)$ \\
After ART & $5(5.0 \%)$ \\
Cesarean delivery & $90(89.2 \%)$ \\
Gestational week at delivery & $31.8 \pm 3.7$ \\
$<37$ weeks & $92(91.1 \%)$ \\
$<34$ weeks & $64(63.4 \%)$ \\
$<30$ weeks & $32(31.7 \%)$ \\
$<27$ weeks & $6(5.9 \%)$ \\
Sum of birth weights (g) & $3,188 \pm 1,051$ \\
$<3,000$ g & $42(41.6 \%)$ \\
$<2,000$ g & $14(13.9 \%)$ \\
$<1,000$ g & $1(1.0 \%)$ \\
Female-female pair & $56(55.4 \%)$ \\
Twin-to-twin transfusion syndrome & $4(4.0 \%)$ \\
Preterm premature rupture of the membranes & $2(2.0 \%)$ \\
Pregnancy-induced hypertension & $2(2.0 \%)$ \\
Short-term outcomes of twin pairs & \\
IUFD/IUFD & $8(7.9 \%)$ \\
IUFD/END & $1(1.0 \%)$ \\
IUFD/Alive & $5(5.0 \%)$ \\
END/END & $1(1.0 \%)$ \\
END/Alive & $3(3.0 \%)$ \\
Alive/Alive & $83(82.2 \%)$ \\
Perinatal mortality rate & $28 / 202(13.9 \%)$ \\
Birthweight discordance (\%) & $10.4 \pm 9.1$ \\
Malformed infants & $13 / 202(6.4 \%)$ \\
\hline Note: ART, assisted reproductive technology; IUFD, intrauterine fetal death; \\
END, early neonatal death within 7 days of life. ${ }^{*}$ For \\
$\quad 83$ twin pairs in \\
whom both twins survived. & \\
\hline &
\end{tabular}

6 ENDs) occurred in 18 women and 174 infants born to 91 women survived 7 days after birth (Tables 1 and 2). Thus, the uncorrected perinatal mortality rate was $13.9 \%$ (28/202).

A double demise including IUFD/IUFD, IUFD/END, and END/END was more likely to occur during the second trimester, while a single demise (IUFD/Alive or END/Alive) appeared likely to occur at any time during gestation (Figure 1). All 10 double demises occurred exclusively at $\leq 29$ weeks of gestation.

A total of $13.9 \%$ of women (14/101) who reached gestational week (GW) $22^{-0 / 7}$ experienced at least a single IUFD (Table 2). The prospective risk of at least a single IUFD was $13.9 \%$ for women who reached gestational week (GW) $22^{-0 / 7}$, gradually decreasing thereafter but remaining at a relatively high level throughout the third trimester (Figure 2).

As the causes of IUFD and END were not specified for some infants, we focused on maternal complications including PPROM, TTTS, PIH, placental abruption, placenta previa, and structural anomalies of the infants. None of the 101 women developed placental abruption or placenta previa, four $(4.0 \%)$ developed TTTS, two $(2.0 \%)$ developed PPROM, and two (2.0\%) developed PIH (Table 1). A total of 13 infants $(6.4 \%)$ had structural anomalies explaining $17.9 \%$ (five infants; Cases 8, 10, and 16 in Table 2) of the 28 perinatal deaths. Other structural anomalies such as otocleisis, cleft lip and palate, cleft lip and upper mandible, 
TABLE 2

Specific Causes of 28 Infant Deaths

\begin{tabular}{|c|c|c|c|c|c|}
\hline \multirow[b]{2}{*}{ Case \# } & \multirow[b]{2}{*}{ GW at delivery } & \multicolumn{2}{|c|}{ Structural abnormalities } & \multicolumn{2}{|c|}{ Outcome (cause) } \\
\hline & & 1st Twin & 2nd Twin & 1st Twin & 2nd Twin \\
\hline 1 & 22 & - & - & IUFD & IUFD \\
\hline 2 & 23 & - & - & IUFD (CE) & IUFD (CE) \\
\hline 3 & 23 & - & - & END (Sepsis) & END (Sepsis) \\
\hline 4 & 26 & - & - & IUFD & IUFD \\
\hline 5 & 26 & - & - & END & Alive \\
\hline 6 & 27 & - & - & IUFD (CE) & IUFD (CE) \\
\hline 7 & 27 & - & - & IUFD & IUFD \\
\hline 8 & 27 & Present \# & Present \# & IUFD & IUFD \\
\hline 9 & 27 & - & - & Alive & END (TTTS, SH) \\
\hline 10 & 28 & Conjoined twinning & Conjoined twinning & IUFD & IUFD \\
\hline 11 & 29 & - & - & IUFD (CE) & IUFD (CE) \\
\hline 12 & 29 & - & - & IUFD (TTTS) & END (TTTS) \\
\hline 13 & 29 & - & - & IUFD & Alive \\
\hline 14 & 31 & Cleft palate & Cleft palate & Alive & IUFD \\
\hline 15 & 32 & - & - & IUFD & Alive \\
\hline 16 & 34 & - & $\mathrm{CDH}$ & Alive & END (PH) \\
\hline 17 & 35 & - & - & Alive & IUFD \\
\hline 18 & 37 & - & - & Alive & IUFD (CE) \\
\hline
\end{tabular}

Note: GW, gestational week; -, absent; \#, unknown details; $\mathrm{CDH}$, congenial diaphragmatic hernia; IUFD, intrauterine fetal death; END, early neonatal death within 7 days of life. The cause of death (CE, cord entanglement; TTTS, twin-to-twin transfusion syndrome; SH, subarachnoid hemorrhage; and PH, pulmonary hypertension) were described as special references on the registered forms. Thus, no description of the cause of death does not imply that these events did not occur in other infants with a poor outcome.

Number of women

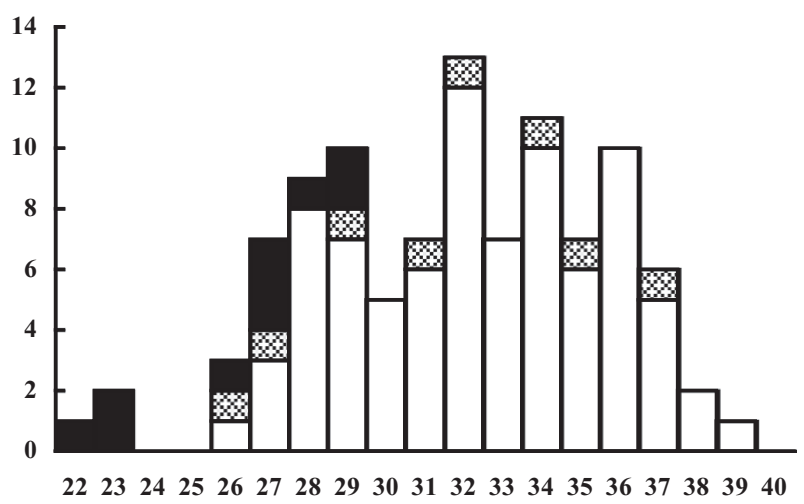

Gestational week at delivery

\section{FIGURE 1}

Distribution of gestational week at delivery and outcome of infant; (black square), double demise including intrauterine death and early neonatal death within 7 days of life; (gray square), single demise including intrauterine death or early neonatal death within 7 days of life; $\square$ (white square), both twins alive at 7 days after birth.

and one lung agenesis not causing infant death were seen in eight infants. TTTS explained $10.7 \%$ (three infants; Cases 9 and 12 in Table 2) of the 28 perinatal deaths. Other causes of death were described in nine infants: seven from cord entanglement (Cases 2, 6, 11, 18 in Table 2) and two from sepsis (Case 3 in Table 2).

\section{Discussion}

Although the policies for managing monoamniotic twins may have varied between hospitals participating in the

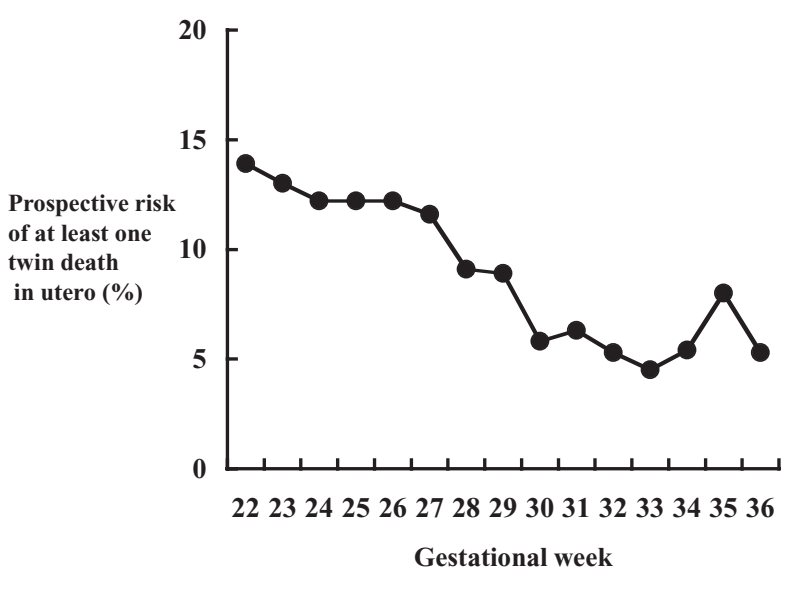

FIGURE 2

Prospective risk of at least a single intrauterine death according to gestational week.

JSOG-SPBRS, the overall perinatal mortality rate was $13.9 \%$ (28/202). Malformation of infants explained 5 of the 28 perinatal mortalities in this study. The prospective risk of at least a single IUFD was $13.9 \%$ for women who reached 22 weeks of gestation, decreasing during the second trimester but remaining relatively high (around 6.0\%) at between 30 and 36 weeks of gestation in this study.

Two reports similar to ours with respect to the maternity number of monoamniotic twins are available (Hack et al., 2009; Heyborne et al., 2005): one included 96 cases in which both twins were alive at 12 weeks of gestation and were delivered between January 1993 and December 2003 (Heyborne et al., 2005); and another included 98 women at $\geq 20$ 


\section{TABLE 3}

Comparison of Infant Outcome in Three Reports Regarding Monoamniotic Twins

\begin{tabular}{llll}
\hline & Heyborne et al. (2005) & Hack et al. (2009) & Present study \\
\hline Study period (year) & $1993-2003$ & $2000-2007$ & $2002-2009$ \\
No. of women at $\geq 22$ weeks & 91 & 92 & 101 \\
No. of female pairs & $60(66.7 \%)$ & $61(66.3 \%)$ & $56(55.4 \%)$ \\
Perinatal mortality & $28 / 182(15.4 \%)^{\S}$ & $27 / 184(14.7 \%)^{\S}$ & $28 / 202(13.9 \%)$ \\
Fetal death & 21 & 12 & 22 \\
$\quad$ Neonatal death & 7 & 15 & 6 \\
$\quad$ Death at $\geq 30$ weeks & $10 / 91(11.0 \%)$ & $11^{*}$ & 5 \\
$\quad$ Double demise & $8 / 91(8.8 \%)$ & $7 / 92(7.6 \%)$ & $10 / 101(9.9 \%)$ \\
$\quad$ Single demise & & $13 / 92(14.1 \%)$ & $8 / 101(7.9 \%)$ \\
Cause of death & $2 * * / 28(7.1 \%)$ & $1 / 27(3.7 \%)$ & $3 / 28(10.7 \%)$ \\
$\quad$ TTTS & $5 / 28(17.9 \%)$ & $7 / 27(25.9 \%)$ & $5 / 28(17.9 \%)$ \\
Malformation & Not specified & $10 / 27(37.0 \%)$ & $7 / 28(25.0 \%)$ \\
\hline Entanglement & &
\end{tabular}

Note: ${ }^{\S}$ these two studies included neonatal deaths within 28 days of life, while the present study included early neonatal deaths within 7 days of life; ${ }^{*}$ includes 5 infants with major anomalies and 1 therapeutic feticide; **attending perinatologist felt that these deaths were due to cord entanglement not TTTS; ${ }^{\top}$ includes double intrauterine deaths, single intrauterine deaths followed by neonatal co-twin death, and double neonatal deaths; ${ }^{\dagger}$ includes intrauterine death and neonatal death; ${ }^{\ddagger}$ includes true knot.

weeks of gestation between January 2000 and December 2007 (Hack et al., 2009). For comparison purposes, only data for women with $\geq 22$ weeks of gestation were abstracted from these two studies (Hack et al., 2009; Heyborne et al., 2005) (Table 3). Table 3 underscores the common features of the three studies. The perinatal mortality rates were very comparable among the three studies, as shown in Table 3. The crude perinatal mortality is around $15 \%$ for women with monoamniotic twins at $\geq 22$ weeks of gestation, although several small studies have reported better outcomes (Baxi \& Walsh, 2010; Cordero et al. 2006; DeFalco et al., 2006; Dias et al., 2010; Pasquini et al., 2006; Rodis et al., 1997).

As shown in the present study, the prospective risk of at least a single IUFD remained high (around 6.0\%) at between 30 and 36 weeks of gestation. Although cord entanglement has been implicated as a cause of fetal/neonatal death, cord entanglement is observed frequently irrespective of the presence or absence of fetal/neonatal demise (Cordero et al. 2006; DeFalco et al., 2006; Dias et al., 2010; Pasquini et al., 2006; Rodis et al., 1997; Suzuki et al., 2001): among 11 monoamniotic twin pregnancies, cord entanglement was seen in two $(67 \%)$ of three pregnancies with IUFD versus seven (88\%) of eight pregnancies without IUFD (Suzuki et al., 2001); among 36 pregnancies, cord entanglement was seen in 15 (42\%) (Cordero et al., 2006); among 20 pregnancies with two live structurally normal twins at 20 weeks of gestation, 19 (95\%) already had cord entanglement at $<20$ weeks gestation and all 40 twins survived perinatally (Pasquini et al., 2006); among 23 pregnancies, cord entanglement was seen in $10(47.6 \%)$ of 21 pregnancies with both-twin survival versus one (50.0\%) of two with IUFD (DeFalco et al., 2006); and cord entanglement was noted in all 13 and 18 monoamniotic twin pregnancies in two reports (Dias et al., 2010; Rodis et al., 1997). Thus, the presence of cord entanglement itself appeared not to affect the outcome of infants with monoamniotic twins. However, monoamniotic twins were likely to exhibit fetal distress or non-reassuring fetal surveillance: 36 (45.6\%) of 79 women and $10(43.5 \%)$ of 23 women underwent a prompt delivery because of fetal distress or non-reassuring fetal surveillance in two reports (DeFalco et al., 2006; Heyborne et al., 2005). Therefore, although not yet verified, many investigators consider that inpatient management and the intensive monitoring of monoamniotic twins and early delivery at 32 to 34 weeks of gestation may improve outcome (Allen et al., 2001; DeFalco et al., 2006; Dias et al., 2010; Heyborne et al., 2005; Lewi, 2010; Pasquini et al., 2006; Rodis et al., 1997).

In the present study, structural anomalies - including one set of conjoined twins - explained a large fraction of the $17.9 \%$ perinatal mortality, consistent with previous studies (Table 3) (Allen et al., 2001; Cordero et al., 2006; Dias et al., 2010; Hack et al., 2009; Heyborne et al., 2005). Apparently, structural anomalies in monoamniotic twins explain a larger fraction of infant deaths than TTTS. TTTS occurs in $10 \%$ of cases and is the main cause of death in monochorionic diamniotic twins (Lewi et al., 2008; Morikawa et al., 2011). However, TTTS is less common in monoamniotic twins, with incidences of 3.1\% (3/96) (Heyborne et al., 2005), 4.0\% (4/101) in the present study, 6.1\% (6/98) (Hack et al., 2009), 8.3\% (3/36) (Cordero et al., 2006), and 9.1\% (1/11) (Suzuki et al., 2001) reported to date.

In conclusion, the present study demonstrated that the prospective risk of IUFD was $13.9 \%$ for women who reached gestational week $22^{-0 / 7}$, gradually decreasing thereafter but remaining at between $4.5 \%$ and $8.0 \%$ between gestational week $30^{-0 / 7}$ and $36^{-0 / 7}$, implying that a considerable number of women experience IUFD at $\geq 30$ weeks of gestation. Structural anomalies of infants explained 17.9\% (5/28) of perinatal deaths, but no structural anomalies were seen in four IUFD infants born to four mothers at $\geq 30$ weeks in the present study. Literature review suggested that the presence of cord entanglement is not a reliable risk factor for perinatal deaths. Inpatient management and the 
intensive monitoring of monoamniotic twins irrespective of the presence or absence of cord entanglement and early delivery at 32 to 34 weeks of gestation may improve outcome.

\section{References}

Allen, V. M., Windrim, R., Barrett, J., \& Ohlsson, A. (2001). Management of monoamniotic twin pregnancies: A case series and systematic review of the literature. British Journal of Obstetrics and Gynecology, 108, 931-936.

Baxi, L. V., \& Walsh, C. A. (2010). Monoamniotic twins in contemporary practice: A single center study of perinatal outcomes. Journal of Maternal Fetal and Neonatal Medicine, 23, 506-510.

Beasley, E., Megerian, G., Gerson, A., \& Roberts, N. (1999). Monoamniotic twins: Case series and proposal for antenatal management. Obstetrics and Gynecology, 93, 130-134.

Cordero, I., Franco, A., \& Joy, S. D. (2006). Monochorionic monoamniotic twins: Neonatal outcome. Journal of Perinatology, 26, 170-175.

DeFalco, L. M., Sciscione, A. C., Magerian, G., Tolossa, J., Macones, G., O’Shea, A., \& Pollock, M. A. (2006). Inpatient versus outpatient management of monoamniotic twins and outcomes. American Journal of Peinatology, 23, 205-212.

Dias, T., Mahsud-Dornan, S., Bhide, A., Papageorghiou, A. T., \& Thilaganathan, B. (2010). Cord entanglement and perinatal outcome in monoamniotic twin pregnancies. Ultrasound in Obstetrics and Gynecology, 35, 201-204.

Hack, K. E., Derks, J. B., Schaap, A. H., Lopriore, E., Elias, S. G., Arabin, B., Eggink, A. J., Sollie, K. M., Mol, B. W. J., Duvekot, H. J., Willekes, C., Go, A. T., Koopman-Esseboom, C., Vandenbussche, F. P., \& Visser, G. H. (2009). Perinatal outcome of monoamniotic twin pregnancies. Obstetrics and Gynecology, 113, 353-360.

Heyborne, K. D., Porreco, R. P., Garite, T. J., Phair, K., \& Abril, D. (2005). Improved perinatal survival of monoamniotic twins with intensive inpatient monitoring. American Journal of Obstetrics and Gynecology, 192, 96-101.

JSOG and JAOG, Minakami, H., Hiramatsu, Y., Koresawa, M., Fujii, T., Hamada, H., Iitsuka, Y., Ikeda, T., Ishikawa, H.,
Ishimoto, H., Itoh, H., Kanayama, N., Kasuga, Y., Kawabata, M., Konishi, I., Matsubara, S., Matsuda, H., Murakoshi, T., Ohkuchi, A., Okai, T., Saito, S., Sakai, M., Satoh, S., Sekizawa, A., Suzuki, M., Takahashi, T., Tokunaga, A., Tsukahara, Y., \& Yoshikawa, H. (2011). Guidelines for obstetrical practice in Japan: Japan Society of Obstetrics and Gynecology (JSOG) and Japan Association of Obstetricians and Gynecologists (JAOG) 2011 edition. Journal of Obstetrics and Gynaecology Research, 37, 11741197.

Lewi, L. (2010). Cord entanglement in monoamniotic twins: Does it really matter? Ultrasound in Obstetrics Gynecology, 35, 139-141.

Lewi, L., Jani, J., Blickstein, I., Huber, A., Gucciardo, L., Van Mieghem, T., Doné, E., Boes, A. S., Hecher, K., Gratacós, E., Lewi, P., \& Deprest, J. (2008). The outcome of monochorionic diamniotic twin gestations in the era of invasive fetal therapy: A prospective cohort study. American Journal of Obstetrics and Gynecology, 199, 514.e1-e8.

Minakami, H., Izumi, A., Tsukahara, T., \& Tamada, T. (1993). Stillbirth risk in Japan. Lancet, 341, 1603-1604.

Morikawa, M., Yamada, T., Yamada, T., Sato, S., \& Minakami, H. (2011). Contribution of twin-to-twin transfusion syndrome to preterm birth among monochorionic biamniotic and bichorionic biamniotic twin pregnancies. Journal of Perinatal Medicine. 39, 557-561.

Pasquini, L., Wimalasundera, R. C., Fichera, A., Barigye, O., Chappell, L., \& Fisk, N. M. (2006). High perinatal survival in monoamniotic twins managed by prophylactic sulindac, intensive ultrasound surveillance, and Cesarean delivery at 32 weeks' gestation. Ultrasound in Obstetrics and Gynecology, 28, 681-687.

Rodis, J. F., McIIveen, P. F., Egan, J. F. X., Borgida, A. F., Turner, G. W., \& Campbell, W. A. (1997). Monoamniotic twins: Improved perinatal survival with accurate prenatal diagnosis and antenatal fetal suraveillance. American Journal of $\mathrm{Ob}$ stetrics and Gynecology, 177, 1046-1049.

Suzuki, S., Kaneko, K., \& Araki, T. (2001). Incidence of intrauterine complications in monoamniotic twin gestations. Archives of Gynecology Obstetrics, 265, 5759. 